\title{
Migration in Sri Lanka: To be recognized as a key enabler for development
}

\author{
Senior Professor Lakshman Dissanayake \\ Vice Chancellor, University of Colombo
}

\section{Linking migration to sustainable development}

Migration is recognized as an important component of population change. Migration is currently built-in to the global development framework, recognizing well-managed migration's integral role in and immense contribution to sustainable development. The Sustainable Development Goals stimulate policy planning and implementation across countries, identifying the interrelationships between migration and development and the vital contributions of migrants ${ }^{1}$. Migration provides a driving force for sustainable development through the effects of globalization. It decreases unemployment and enrich human capital. International migration has come to play a central role in the social, economic, and demographic dynamics of both immigrant-sending and immigrantreceiving countries. With the increasing migration trends, governments, nongovernmental sector and private sector increasingly appreciate the relevance of migration to all aspects of sustainable development. Migration is normally recognized as a process which provides benefits to both sending and receiving areas. At the same time, it can also provide trade-offs and costs to migrants themselves, their families and societies. Furthermore, it also can create inequalities and vulnerabilities, particularly when access to regular migration opportunities is not open to everyone and when migration is forced to transpire in disastrous situations. In this context, it is particularly essential to protect, respect migrants' human rights because migrants, especially women who are low-skilled and those who are recognized as forced migrants are missed out from most of the national development policies.

During the recent past, international and internal migration has gradually been accepted as a constructive force for development, because migrants tend to transfer knowledge and

\footnotetext{
${ }^{1}$ http://unofficeny.iom.int/2030-agenda-sustainable-development
} 
FGS - CJMR Colombo Journal of Multi - Disciplinary Research

skills to both receiving and origin locations, improve investments and remittances, and promote economic linkages and business opportunities between countries and regions ${ }^{2}$. Sensibly accomplished migration can stimulate economic growth and innovation in destination locations, and poverty reduction in origin settings. Simultaneously, to some extent, migration can offset labour surpluses in sending countries, as well as receiving countries can manage their deficient labour markets. Connecting the opportunities that migration provides to sustainable development requires countries to create policy and related legal backgrounds that identify the patterns and drivers of migration, as well as the characteristics of migrants themselves.

It is quite important to note that migration has been explicitly incorporated into the SDGs with the adoption of the 2030 agenda for Sustainable Development Goals ${ }^{3}$ :

* Respect the human rights for all migrants, regardless of their migration status

* Take into account the vulnerabilities of migrants, refugees and internally displaced persons

* Recognize the contribution of migration for global sustainable development

* Address forced displacement and humanitarian crises

- Promote international cooperation

* Strengthen the resilience of host communities

* Support the right of citizens to return to their country of origin

\section{Internal Migration: Largely neglected aspect}

Patterns: Internal migration has been playing a major role in redistributing the population in Sri Lanka stemming from the introduction of colonization schemes during the immediate post-independence period. The redistribution has taken place with the development and expansion of towns both as commercial and administrative centers that attracted large numbers of people to urban areas because of village expansion through colonization or land development schemes which shifted people away from the densely

${ }^{2}$ https://sustainabledevelopment.un.org/content/documents/544brief15.pdf

${ }^{3} \mathrm{http}: / /$ www.un.org/en/development/desa/population/migration/publications/populationfacts/docs/Migration PopFacts20155.pdf 
populated districts of the country (International Organization of Migration, 2005). Besides, migratory movements also have occurred from the northern and eastern provinces of the country to other areas due to the civil disturbances that prevailed for three decades since the 1980s. Figure 1 shows the incessant consequence of colonization schemes by having a larger migration streams for dry-zone districts. Displacement and resettlement of the displaced people have led to upsurge in-migration especially in Vauniya, Mullaitivue and Killinochchi districts.

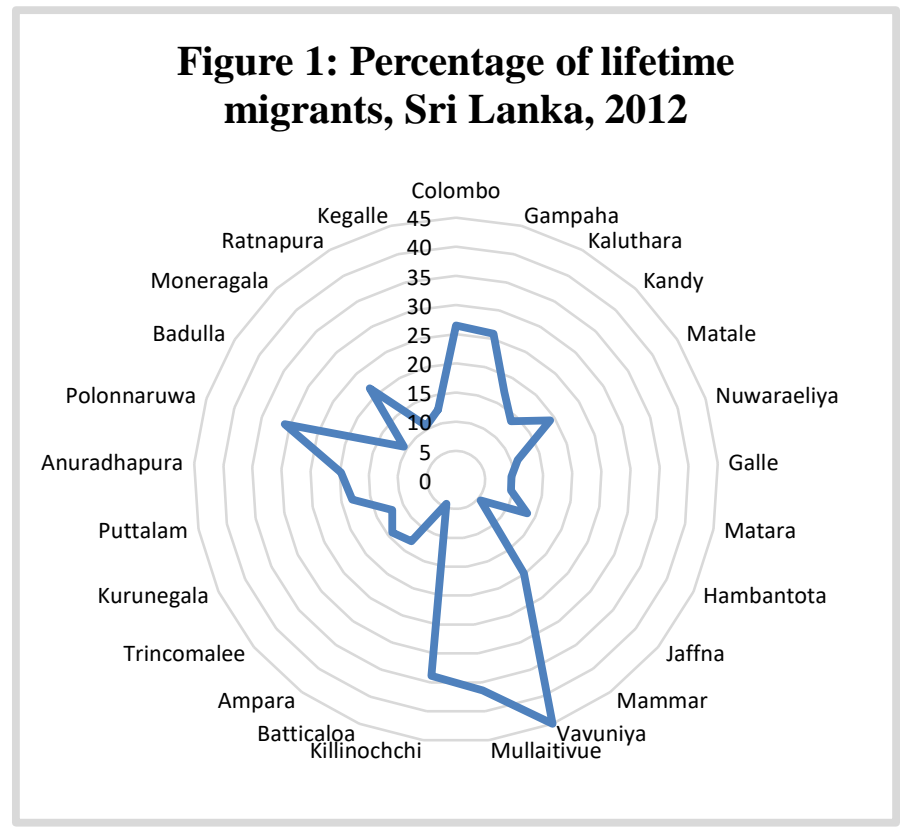

Source: Author's calculations using data obtained from Department of Census and Statistics

Marriage and Employment: Key drivers for migration: Many rapidly expanding Asian economies have observed increases in the rate of internal migration over the past two decades, because of declining job opportunities in rural areas and increased opportunities in urban areas (ODI, 2006). This can be true for Sri Lanka as well since the country moved from lower income status to middle-income country standing during the last decade. Dramatic improvements in communication and transport have allowed for significant levels of large-scale internal movement in Asian countries including Sri Lanka. Many factors driving this migration are common to both permanent and circular migration, including regional inequality, under-employment in rural areas and the growth 
FGS - CJMR Colombo Journal of Multi - Disciplinary Research

of labour intensive industries such as those established in free-trade zones in Sri Lanka where many girls migrated from rural areas to find employment. Sri Lankan internal migration pattern observed in 2012 census shows that second highest reason for migration is employment (19.4 percent) and about 32 percent of all migrants have either moved to Colombo district where the country's capital is positioned or Gampaha district, which is an adjoining district to the former where majority of the free-trade zone industries are located. It has also been reported that nearly half of female migrants who moved to the district of Colombo originated from the south-western coastal districts of Kalutara, Galle and Matara and the adjacent district Gampaha. Moreover, migration flows to Colombo from the southwestern coastal belt were already well established since 1946 (International Organization of Migration, 2005). However, it appears that the study of female migration has been neglected in Sri Lanka although women constitute a considerably superior proportion than men in internal migration.

The relationship between income and internal migration seems to be clearly visible as depicted in Figure 2 and the Pearson correlation coefficient ${ }^{4}$ of +0.72 , which suggests a significant positive association. In other words, it explains that the higher the inmigration, higher the income would be. Furthermore, about 51 percent of the district variation of median income is explained by district variation of in-migration in Sri Lanka. This shows that in-migration significantly contributes to improve the income level of the destination areas. In the absence of nationally representative data exists on internal remittances, the above evidence suggests that migration can reduce poverty, inequality, and contribute to economic growth and development. Although there is growing recognition that migration can play a role in reducing poverty (UN, 2005), detailed research on how migration contributes to development is lacking in Sri Lanka. By looking at the district variation in poverty and in-migration, one can observe that 30 percent of district variation in poverty head count ratio can be explained by the district variation of in-migration in Sri Lanka. Even though in-migration does not reduce poverty directly, remittances may help to sustain rural livelihoods by preventing people from sliding further into poverty because of dependence on a deteriorating agricultural base

\footnotetext{
${ }^{4}$ The Pearson product-moment correlation coefficient is a measure of the strength of the linear relationship between two variables.
} 
(Overseas Development Institute, 2006). Remittances also can stimulate the land market in the sending areas, increase local wages and the demand for local goods and services, and generally improve the economy (Black et al., 2005).

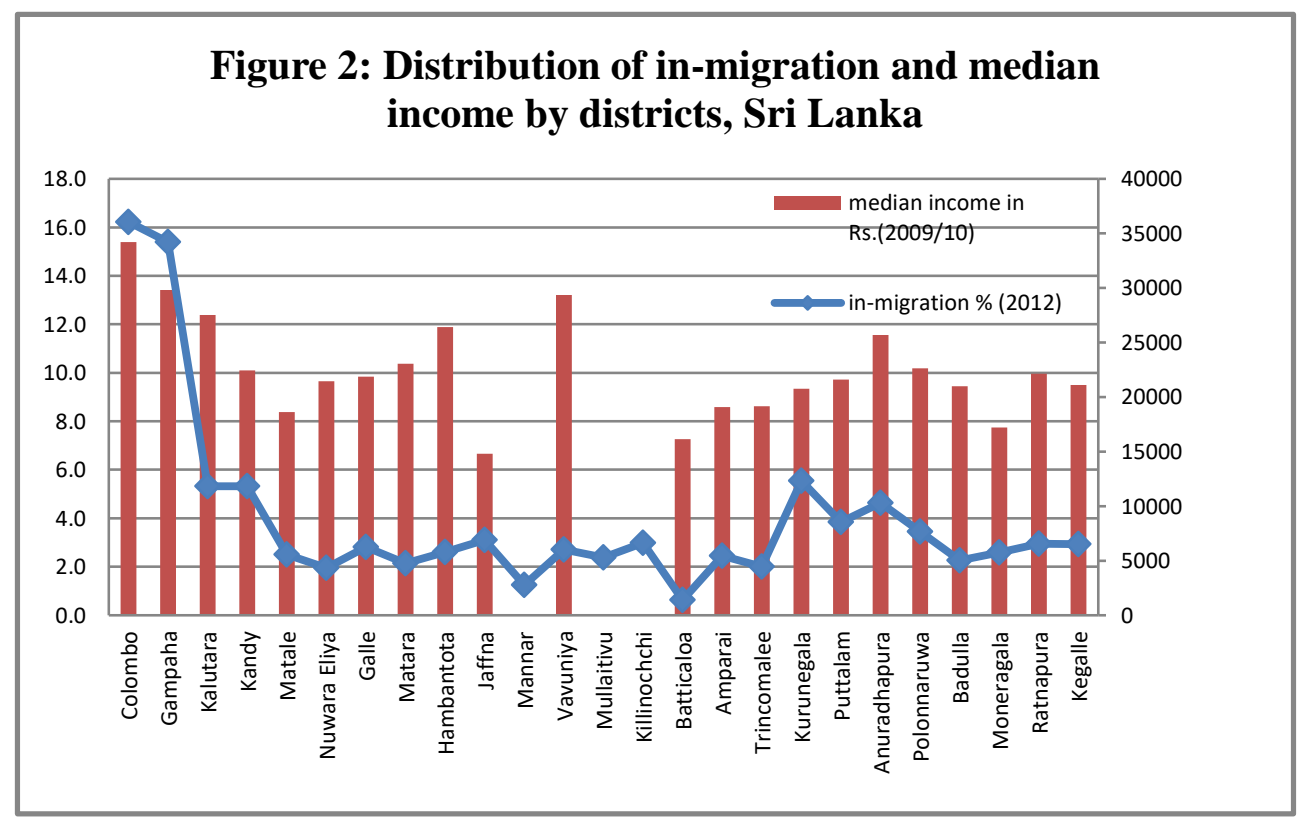

Source: Author's calculations using data obtained from Department of Census and Statistics

Overall, the recent census information on migration shows that 19 percent of population $(3,861,787)$ has migrated to another district from their district of birth. Majority of females migrate due to marriage (43.5 percent) while majority of males migrate for employment (30.6 percent). Reasons for migration are depicted in figure 3 . This suggests that internal migration in the country is mainly governed by marriage, and employment. 


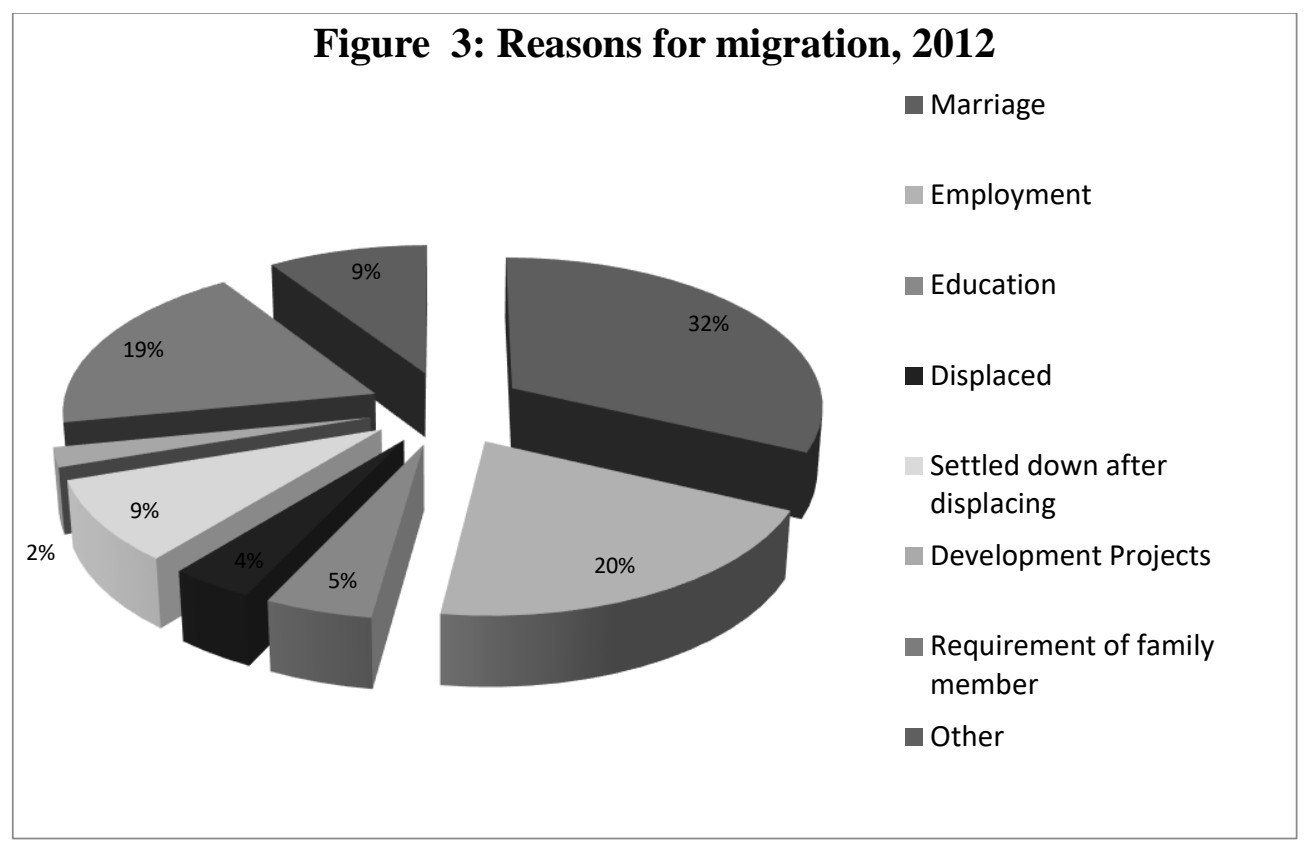

Source: Author's calculations using data obtained from Department of Census and Statistics

\section{Nexus between internal migration, spatial distribution and development: Dynamism essential for policy makers}

Spatial distribution of population and development are exceedingly interconnected, particularly in the context of sustainability. Migration is an essential constituent of the spatial distribution of a population and is likely to continue as a key driver in the coming decades, predominantly as a component of urbanization in developing countries. When the relationship between migration and spatial distribution is explored, the process of urbanization becomes very important because the process of urbanization is an intrinsic dimension of economic and social development and, in consequence, both developed and developing countries are going through the process of shifting from predominantly rural to predominantly urban societies and Sri Lanka is not an exception. With urbanization in Sri Lanka expected to increase from 15 percent in 2001 to 60 percent in 2030, it is highly likely to experience potential environmental side effects if proper urban planning is not in place. However, Sri Lanka is very optimistic about the initiatives taken by the Urban Development Authority which may mitigate some of the negative effects and create a sustainable urban development through innovative locally driven initiatives. Presently, a strong association is discernible between the spatial distribution and in-migration of the 
country when district-wise analysis is performed. Figure 4 presents the district-wise population densities and percentage distribution of in-migration. It shows that spatial distribution of population and in-migration are highly related to each other. When this relationship is examined further in statistical terms, it was found that 74 percent of the district variation of spatial distribution of the country is explained by the district variation of in-migration. Moreover, these two components demonstrate Pearson's correlation coefficient of +.86 , which shows that in-migration in Sri Lanka significantly contributes to the growth of population density throughout the country.

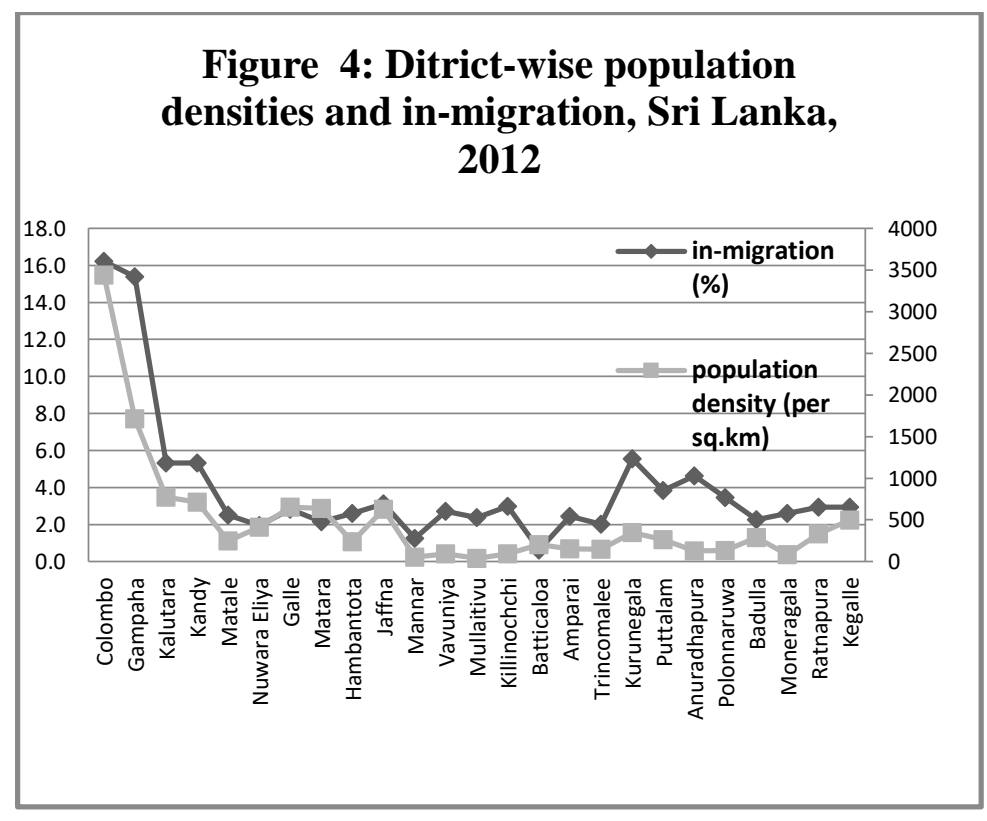

Source: Author's calculations using data obtained from Department of Census and Statistics

A proper knowledge on spatial distribution of population and its dynamisms is essential for policy makers to introduce socio-economic and infrastructural oriented policy interventions. The interdisciplinary character and the shifting regional impact of demographic change advocate that it is an appropriate priority for regional policy interventions. Spatial distribution can be looked at from a labour market perspective by linking territorial differentiation in economic activity rates, issues of labour supply and the provisions of skills. Demographic processes can also have important implications for the spatial planning components of regional policy. The provision of social infrastructure 
FGS - CJMR Colombo Journal of Multi - Disciplinary Research

and technical infrastructure are usually a policy competence of regional levels and thus needs to be tailored to respond to the differentiated territorial impact of demographic change. There is a possibility that demographic changes can create tensions amongst different ethnic groups and this can have a territorial dimension where different populations are concentrated in particular areas. Therefore, proper understanding of spatial distribution is an important issue for contemporary regional development policy.

\section{Natural Disasters and Internal-displacement: Protection is a responsibility}

Sri Lanka has been always into a climatic-affected hazardous situation as it is located in the Indian Ocean by encountering two monsoons. The most common hazards experienced in Sri Lanka were floods mostly arising from monsoonal rain or effects of low pressure systems and droughts due to failure of monsoonal rain. Sri Lanka is also prone to hazards such as landslides, lightning strikes, coastal erosion, epidemics and effects of environmental pollution. The impact of climate change can exert adverse effect on agriculture in Sri Lanka thereby increasing severity of food scarcity. The impacts of climate change such as unusual forest fires, floods, drought, and erratic rainfall have been reported in Sri Lanka which potentially affect the natural ecosystem as well as local livelihoods. Rice is the staple food in Sri Lanka and produced at the top end of the optimum temperature range for cultivation which means that the anticipated increases in temperature can have a deep effect on yields. Estimates suggests that rice yield could be reduced by approximately 5.9 percent if air temperature increased by $.5^{0} \mathrm{C}$. Sri Lanka has already experienced $.64^{0} \mathrm{C}$ increase of air temperature during the last 4 decades $^{5}$. Rainfall plays an important role in agriculture as any shortages of excess of rainfall lead to a reduction in yields. A small reduction in rainfall can cause a significant decrease in ground water replenishment with huge implications for intensive, lift-irrigation dependent agricultural production in Sri Lanka's sandy soil regions such as Kalpitiya and Jaffna Peninsula ${ }^{6}$. In the other hand, soil erosion and especially, the loss of productive topsoil is also likely during heavy rainfall events. It has been suggested that mean annual temperature is projected to increase by $1.0^{\circ} \mathrm{C}^{7}$. Mean rainfall is projected to change by 4

\footnotetext{
${ }^{5}$ www.wamis.org/agm/meetings/.../S406-Chandrapala_Sri-Lanka.pdf

${ }^{6}$ weadapt.org/...base/.../policy-briefing-on-climate-change-in-sri-lankaCached

${ }^{7}$ sdwebx.worldbank.org/.../wb_gfdr__climate_change_country_profil...
} 


\section{Migration in Sri Lanka: To be recognized as a key enabler for development}

percent with a possible decline compared to historical records, with associated changes in the quantity and spatial distribution of rainfall ${ }^{8}$. It is apparent that climate variability and extreme events across Sri Lanka will increase in the future. Occurrence of floods and droughts during the period 1974-2004 showed a significant increase while floods and droughts have affected more than 10 and 6 million people, respectively.

Severity of landslides also has increased during the recent times especially in the highland regions through a combination of heavy rains, geological changes in the hill country, and deforestation. Landslides are common in the districts of Badulla, NuwaraEliya, Ratnapura, Kegalle, Kalutara, Kandy, and Matale. Sea level rise, storm surges, and coastal erosion are greatest in the west, south-west, and southern coastal belt where about 50 percent of Sri Lanka's population is settled. It has been shown that Sri Lanka is currently experiencing an erosion rate of .30 to $.35 \mathrm{~m}$ per year in 45 to 55 percent of the coastal belt ${ }^{9}$. In addition, cyclones often affect the northern region of the country, especially during the months of November and December. Although there was no such historical evidence of high magnitude cyclones, projected changes offer an increased frequency and magnitude of cyclones and other climate-related disasters. Although the 2004 tsunami was not a climate-related phenomenon, it caused brutal damage in the coastal areas adding to the shocks from storm flows ${ }^{10}$.

In 2004, almost two-thirds of the Sri Lankan coast was affected by the Indian Ocean tsunami highlighting the country's susceptibility to low-frequency but high impact dealings. According to the information available on the people affected by natural disasters during the period 1974-2004 is illustrated in figure 5, which clearly identifies floods, drought, storm and landslides as the most common natural disasters in Sri Lanka.

\footnotetext{
${ }^{8}$ www.wamis.org/agm/meetings/.../S406-Chandrapala_Sri-Lanka.pdf

${ }^{9}$ www.wamis.org/agm/meetings/.../S406-Chandrapala_Sri-Lanka.pdf

${ }^{10}$ sdwebx.worldbank.org/.../wb_gfdrr_climate_change_country_profil...
} 
Figure 5: People affected by different disasters in Sri Lanka, 1974-2004

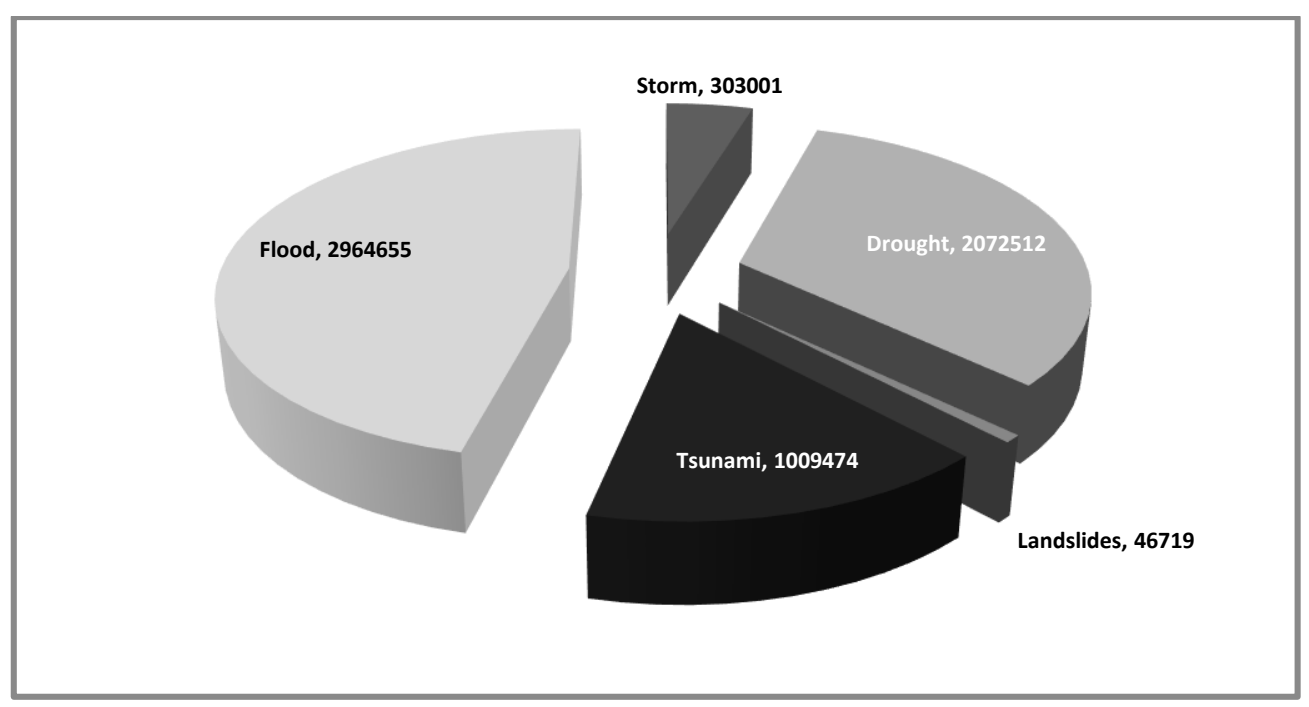

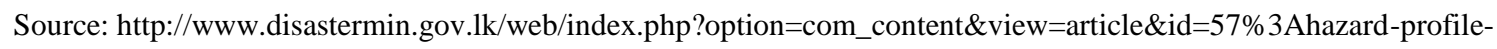
of-sri-lanka\&catid=73\%3Areports\&Itemid=70\&lang=en

The impacts of droughts, floods, landslides, and cyclones include long-term and economy-wide adverse consequences, widespread crop failure/loss outbreaks of human and animal diseases, dislocation of human population, destruction of property and infrastructure loss to livelihoods, shorter growing season, destruction of sensitive ecosystems and biodiversity. Amplification in the frequency and intensity of natural disasters will have massive socio-economic impacts on urban areas and human settlements. Since 60 percent of Sri Lanka's population is expected to reside in urban settlements by 2030, it is critical to guarantee that such developments are effectively climate-proofed to ensure long term sustainability.

The needs and vulnerabilities of those who were forcibly displaced due to natural disasters are different to those who voluntarily migrate and hence there is a necessity to 


\section{Migration in Sri Lanka: To be recognized as a key enabler for development}

have a different policy framework for their protection. This suggests a differentiated policy, which will allow humanitarians and development actors to build on existing laws and response apparatuses and thus strengthening the existing international system to better address specific needs of those affected by natural disasters ${ }^{11}$.

\section{International Migration: Not limited to unskilled labour migration}

A leading emigration nation: Sri Lanka is one of the contemporary world's major emigration nations. The United Nations (2013) has shown that there were 1.25 million Sri Lanka-born persons living outside of their country of birth, equivalent to 5.9 percent of the current Sri Lankan resident population. Jayasuriya and McAuliffe (2013, 6-7) showed that migration outflows of Sri Lankans can be categorized into five groups such as Temporary workers (skilled, semi-skilled and unskilled), Skilled settlers, Student migration, Asylum seekers and Tourists, including pilgrimages to Nepal and India. Since several of these flows are temporary or circular, not all are captured in the United Nations' estimates of the numbers of Sri Lanka-born persons resident outside of Sri Lanka. Contract labour migration of low skilled workers, especially female domestic workers to the Middle East, and a lesser extent, Southeast and East Asia, has increased over the years (Hugo and Dissanayake, 2014).

\section{Trends and Patterns}

Emigration towards more developed regions: Sri Lanka can be regarded as one of the significant emigration nations of the world today (Hugo, 2013). According to the United Nations recent data, there were 0.8 million Sri Lanka-born persons living outside of their country of birth in 2000 but increased to 1.3 million by 2013 (United Nations, 2013). This was a 51 percent increase during the 13 year time period and the increase was substantial for the more developed regions as it was 158.3 percent whereas the less developed regions recorded only a 2.7 percentage change. This suggests that the emigration was dominant towards more developed regions during the last two decades.

\footnotetext{
${ }^{11}$ Guiding Principles on Internal Displacement, United Nations Publication E/CN.4/1998/53/Add.2,1998
} 
FGS - CJMR Colombo Journal of Multi - Disciplinary Research

This needs a greater attention as this aspect has been neglected when analyzing international migration trends in Sri Lanka.

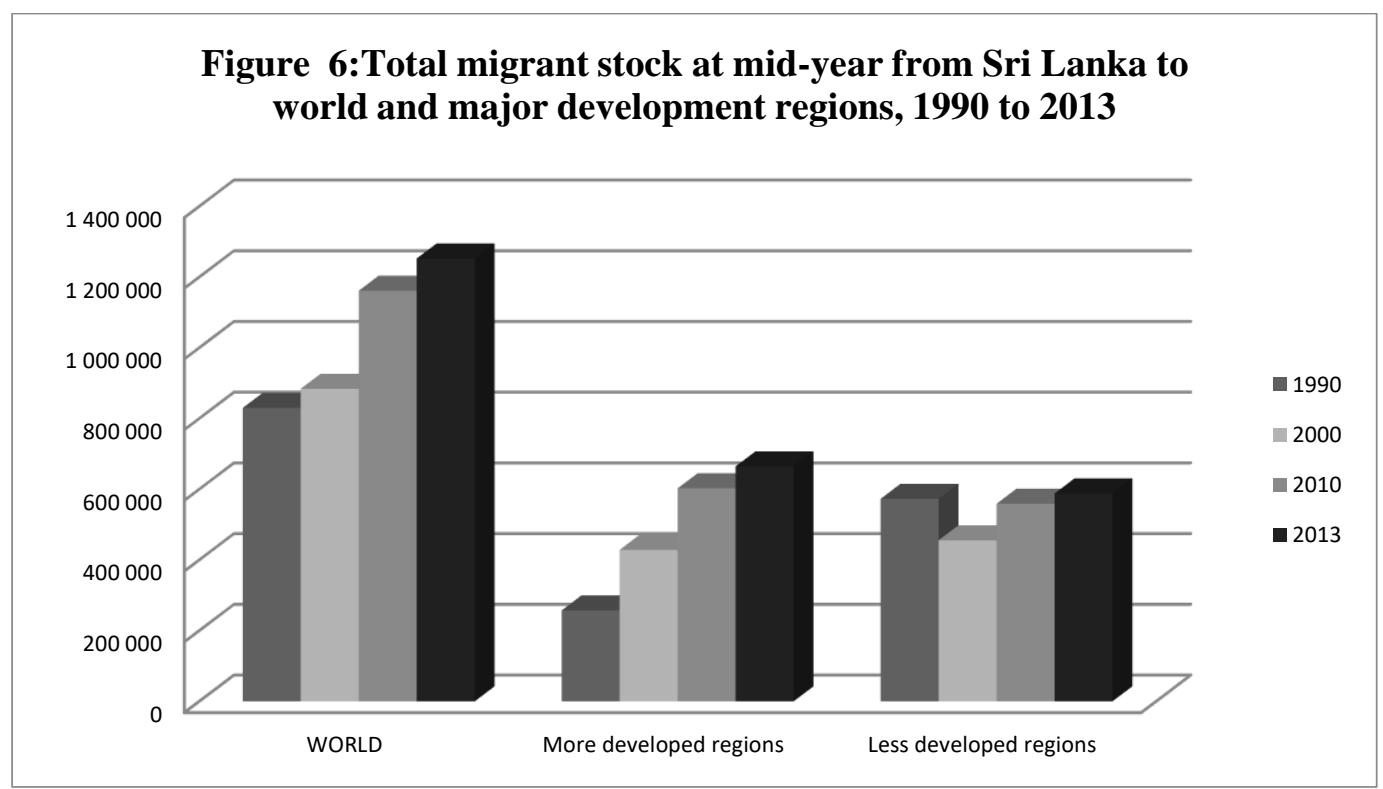

Source: Trends in International Migrant Stock: The 2013 Revision, United Nations, Population Division (www.un.org/en/development/desa/.../international-migration/index)

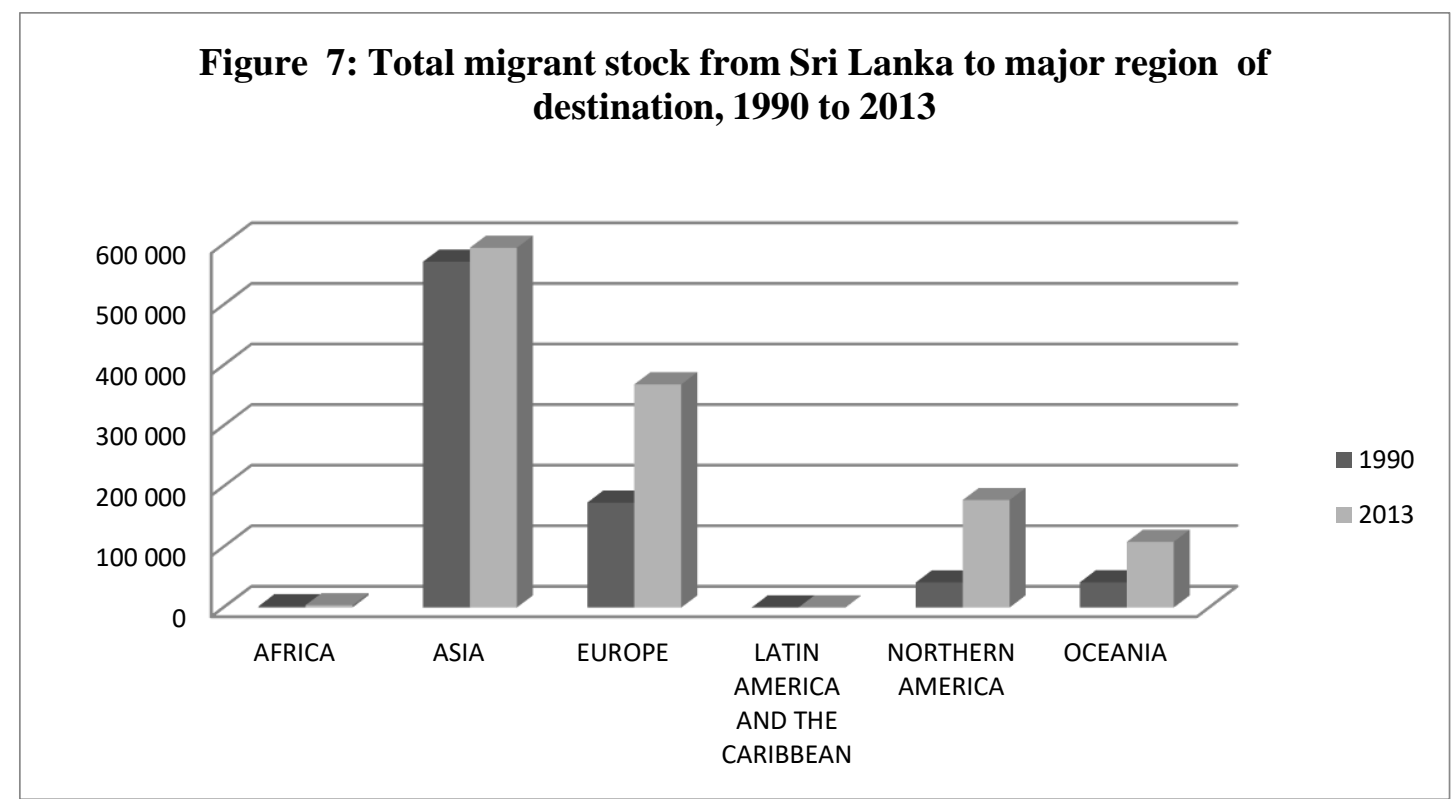

Source: Trends in International Migrant Stock: The 2013 Revision, United Nations, Population Division (www.un.org/en/development/desa/.../international-migration/index) 


\section{Migration in Sri Lanka: To be recognized as a key enabler for development}

Further analysis reveals that Sri Lanka's emigration has been dominant towards Northern America, Oceania, Europe and Africa. In the Northern America, it was only Canada and the United States receiving Sri Lankan migrants. In 1993, Canada accounted 61.1 percent of the Sri Lankan total emigration to that region while the United States of America recorded 38.9 percent contribution. In 2013, this was 70 and 30 for Canada and the United States of America, respectively, providing more dominance towards Canada. The emigration flow for Canada was very significant as it was a fivefold increase from 1990 to 2013 whereas the United States showed only threefold growth. A substantial proportion of Tamil migration to Canada was observed because of the 30 year-long war in Sri Lanka. According to the Canadian 2011 census, Tamil population of Canada was 143,000 and become the 16th largest immigrant language group in Canada ${ }^{12}$. Percentage increase in Tamil population from 2006 to 2011 was 21.3 percent and Tamils had the 13th highest immigrant language growth in Canada.

Although all European regions are attracted to Sri Lankan migrants except the Eastern Europe, Northern and Southern European regions show a marked increase during the recent years. Among the Northern European countries, the United Kingdom has been the most attractive destination for the Sri Lankan emigration during the period 1990 to 2013. Sri Lankan emigration to the United Kingdom during these twenty three years has contributed 88.6 percent to the total change observed for the whole Northern European countries. In addition to those who migrated as students and skilled professionals, there has been an influx of Tamil population migrating to the United Kingdom during the war years seeking for refugee and asylum status. Furthermore, Norway, Denmark and Sweden offered asylum to number of Sri Lankan Tamil migrants during the war years.

\footnotetext{
12 http://tamilculture.ca/tamils-by-the-numbers/
} 
FGS - CJMR Colombo Journal of Multi - Disciplinary Research

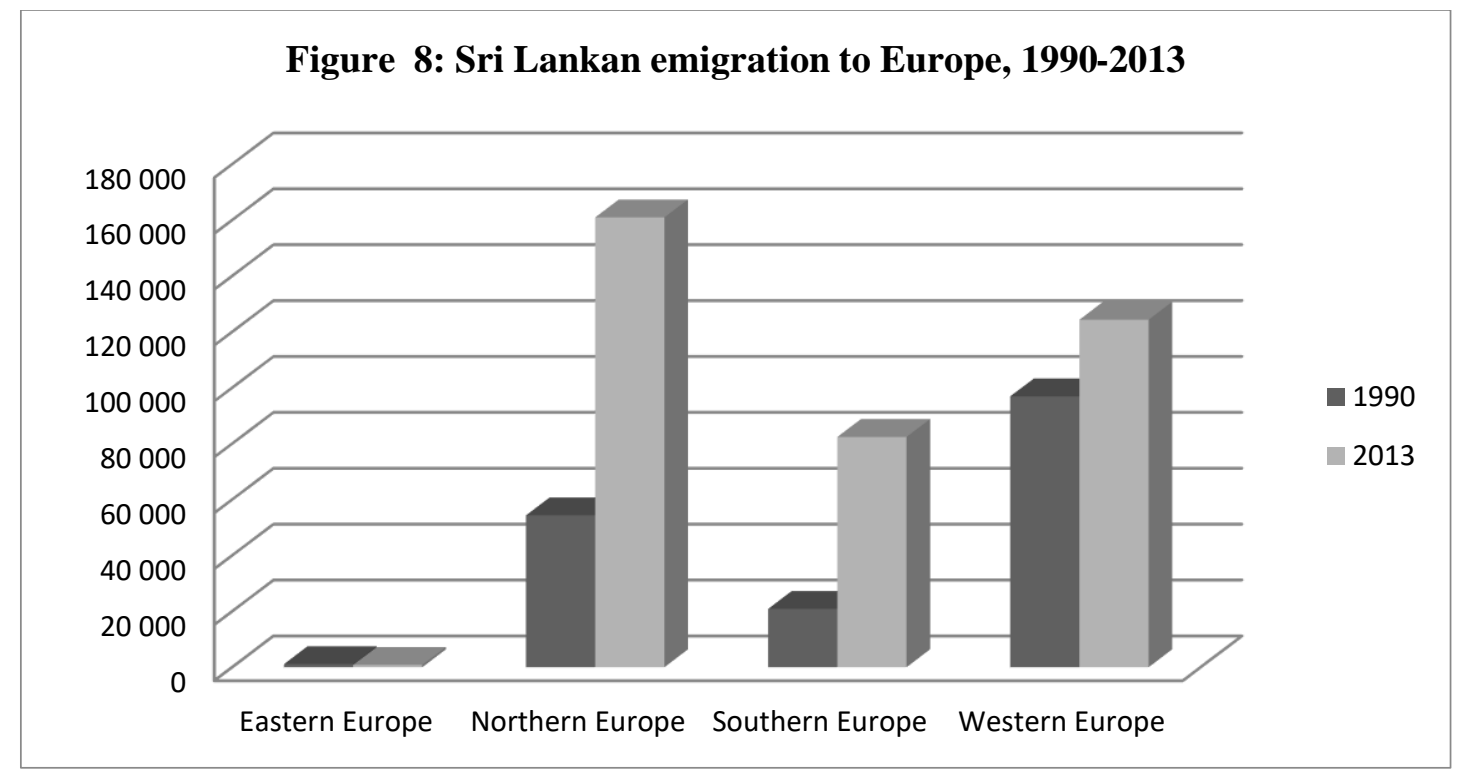

Source: Trends in International Migrant Stock: The 2013 Revision, United Nations, Population Division (www.un.org/en/development/desa/.../international-migration/index)

The growth of Sri Lankan emigrants to Oceania has been mainly towards Australia by accounting more than 90 percent both in 1990 and 2013. Figure 9 shows that there was a significant increase of the migrants stock of Sri Lankan emigrants in Australia. This was a more than twofold increase with 59,833 more migrants in 2013 from 1993.

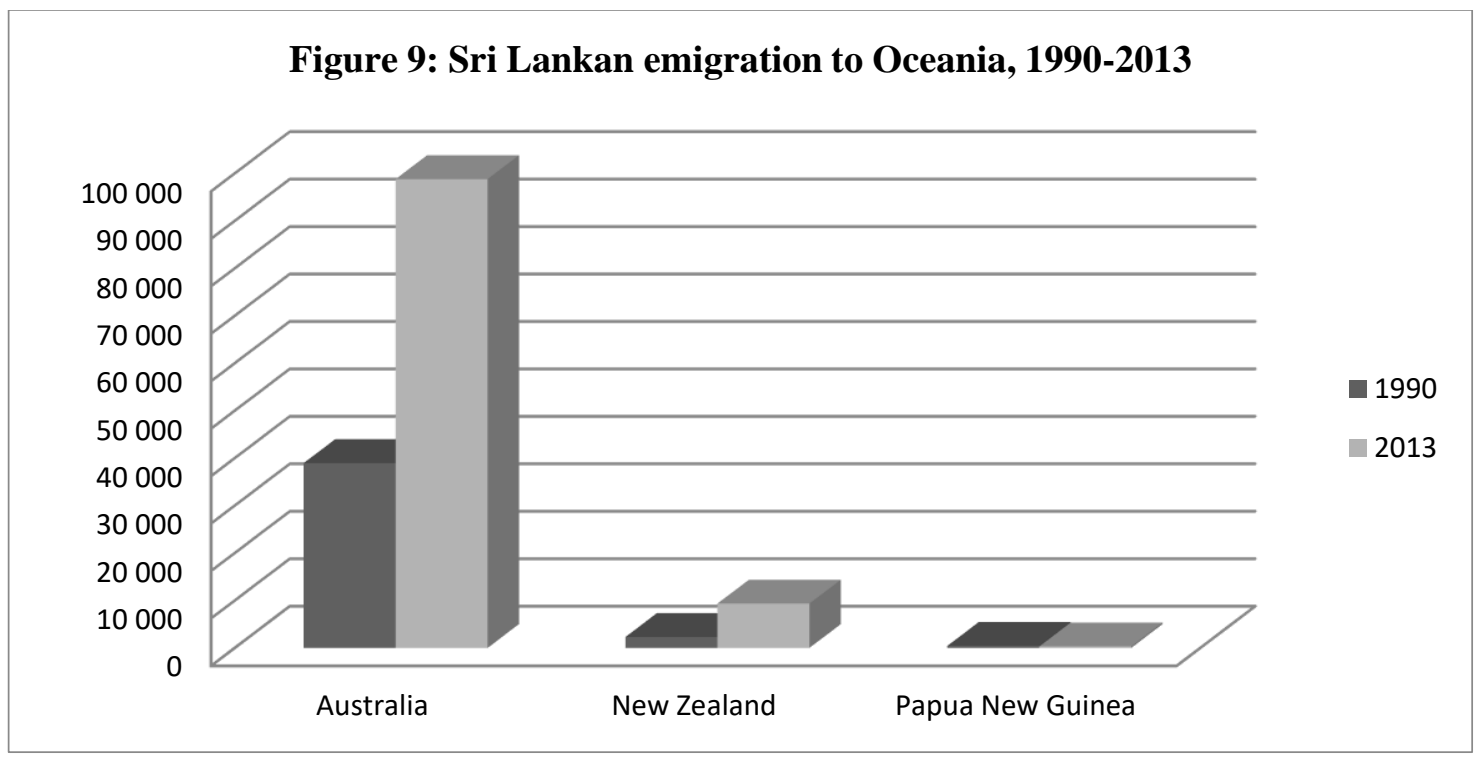

Source: Trends in International Migrant Stock: The 2013 Revision, United Nations, Population Division (www.un.org/en/development/desa/.../international-migration/index) 
Emigration to Asia: Sri Lankan emigration to Asia has been more significant both in 1990 and 2013 with even a slight increase during the latter year. Although the percentage change of emigration to Asian countries has been very low, it records the highest volume of migration. Amongst the Asian countries, Southern and West Asian regions have been the most attractive destination for Sri Lankan migrants. Sri Lankan emigration to Republic of Korea contributed 62.9 percent to the total change of Sri Lankan emigration between 1990 and 2013 to the East Asian countries. This was due to the opening up of employment opportunities for Sri Lankan labour in the Republic of Korea during the recent years.

Southern and Western Asian regions have been very attractive regions for Sri Lankan migrants because those two regions contributed 62.3 percent of the Sri Lankan emigrants to Asia in 2013. Sri Lankan emigration to India has been dominant throughout the history and this was significantly reflected during the conflict time due to large number of Sri Lankan Tamils migrating as refugees to Southern Indian State of Tamil Nadu. However, the decline of the number in India was due to return of some emigrants after the conclusion of the war in 2009.

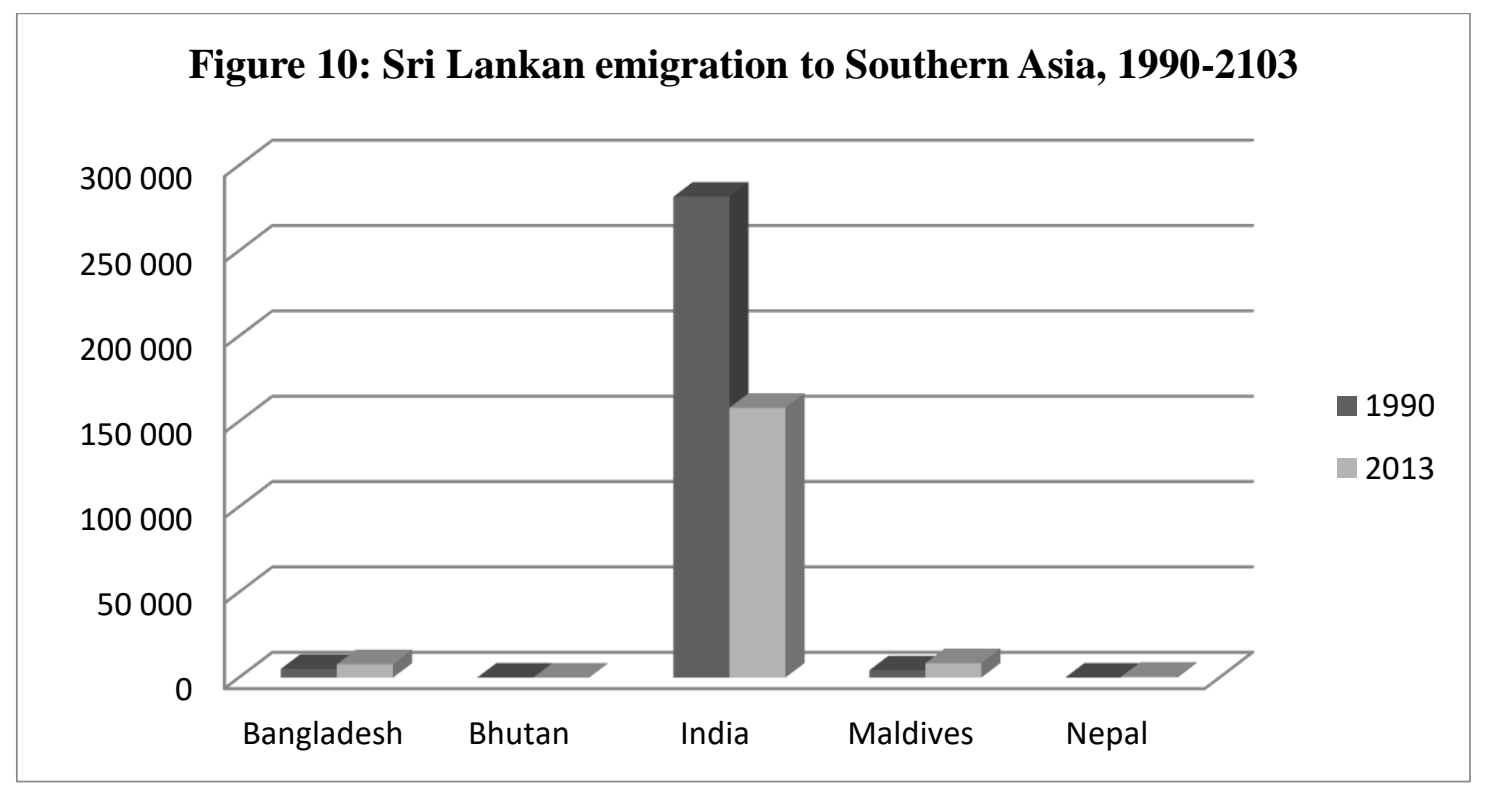

Source: Trends in International Migrant Stock: The 2013 Revision, United Nations, Population Division (www.un.org/en/development/desa/.../international-migration/index) 
FGS - CJMR Colombo Journal of Multi - Disciplinary Research

Western Asia became attractive to Sri Lankans because of the unskilled/semi-skilled labour employment opportunities available in those oil-rich countries in the region. Migration stock has grown by adding 89,972 during the period 1990 to 2103 . Figure 7 shows that the largest number of Sri Lankan emigrants resides in Asia. Amongst the Asian region, West Asian region is the most attractive destination. Figure 11 illustrates that Saudi Arabia, United Arab Emirates and Kuwait are the major countries that attract labour migration.

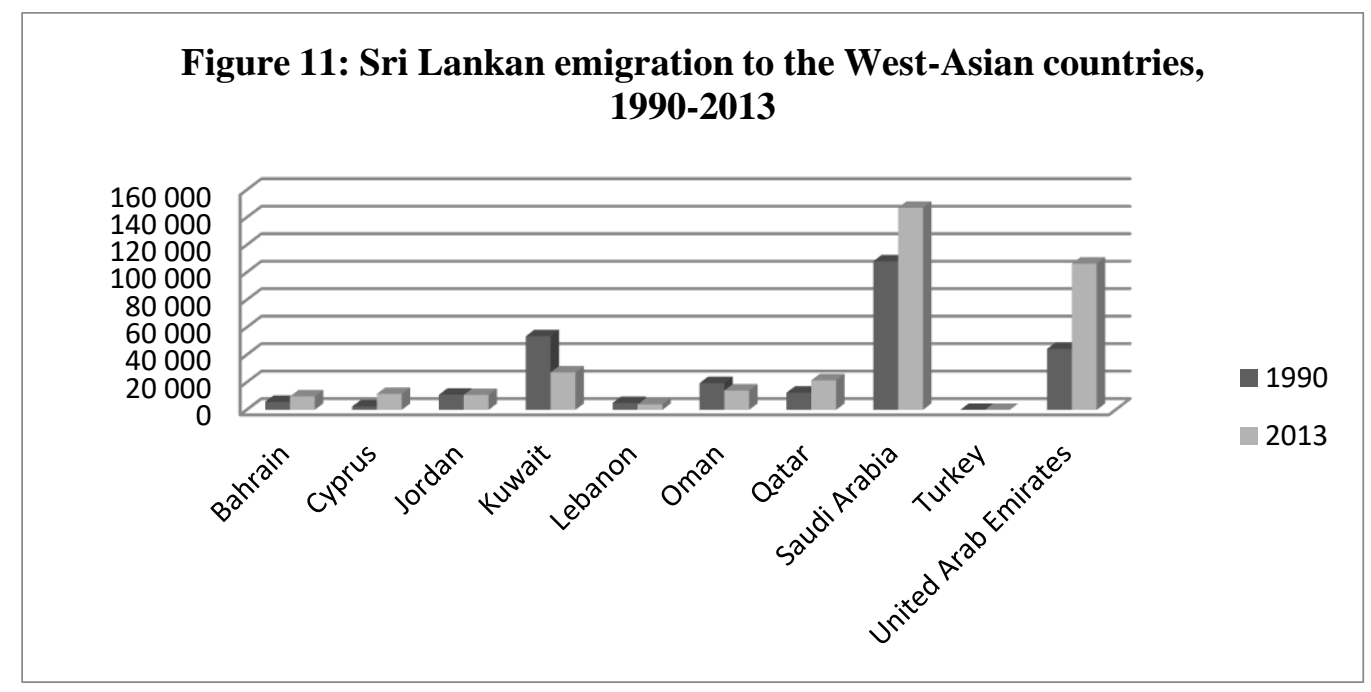

Source: Trends in International Migrant Stock: The 2013 Revision, United Nations, Population Division (www.un.org/en/development/desa/.../international-migration/index)

Irregular Migration: Boat migration or Irregular Migration Arrivals is not a recent phenomenon which is specifically developed for Australia. Although Australia is presently the preferred destination of these smuggled migrants, Italy was one of the major destinations in the past. Australia has become a very attractive destination to irregular migrants who seek refugee status. Most importantly, in recent years, it was not only Tamils who were involved with boat migration but Sinhalese as well. The number of Sri Lankan irregular migrants reported in Australia would have increased more if the Sri Lankan authorities have not taken preventive actions in Sri Lanka itself before the irregular migrants leave the country or capturing them while in the sea before crossing Sri Lankan border. 


\section{Migration in Sri Lanka: To be recognized as a key enabler for development}

Available literature on factors influencing irregular maritime migration is dominated by the idea that economic motive as the major reason while few studies highlighted that political or protection issues in Sri Lanka has driven Northern Tamils to make such move. The general understanding of the population is that overseas migration can bring prosperity to the family because international migration has uplifted the socio-economic status at family level. This suggests that the idea that international migration brings prosperity' has become a norm, especially among the Sri Lankans who are at the lowest socio-economic category. Most importantly, the international labour migration and the boat migration to Italy have made a substantial impact on irregular maritime migration to Australia because of the benefits drawn from unskilled labour. Although some argue that motive of these migrants are political but Hugo and Dissanayake's study (2014) clearly finds the major reason for irregular migration is economic.

Migration has become a strong element in the Sri Lankan culture with the notion that 'overseas migration can bring fortune'. Therefore, Sri Lankans will continue to migrate with legal or illegal means without even knowing where they migrate but to any foreign destination (Hugo and Dissanayake, 2014).

A major contributor to development: International migration provides benefits such as the remittances, the income that migrants send home (Taylor, 2006). It has been frequently cited that significant flows of relatively low skilled workers whose productivity and wages are far higher at the destination countries than at home. Development economists argue that migration and the flow of remittances, as well as the experience, skills and knowledge of returning migrants would facilitate sending regions in developing countries in their economic take-off (Penninx 1982, Beijer, 1970; Kapur, 2003; Ratha 2003; World Bank 2006). Massey (1988) argued that once emigration begins it can promote changes in social and economic structures that make extra outmigration more likely.

Linkages between Sri Lanka and its diaspora have become increasingly important. A major dimension of this has been the sending of remittances to Sri Lanka by expatriates overseas on a permanent or temporary basis. Remittances make up 10 percent of the 
FGS - CJMR Colombo Journal of Multi - Disciplinary Research

national GDP. On average, Sri Lanka received around 7.2 billion US Dollars as its foreign labour remittances in $2016^{13}$. It was also reported that the inflows by way of workers' remittances significantly contribute to finance 85 percent of the trade deficit of the country ${ }^{14}$. Remittance from foreign employment contributes to 36 percent of export earnings. Its share to the GDP is around 7 percent (Ministry of Finance and Planning, 2012).International migration, has thus become a significant and potentially beneficial component of Sri Lanka in its development framework. The increase in the migration of skilled workers, enhancement of the availability of formal channels, with the increased number of bank branches and service offices in the conflict affected provinces, to remit funds to Sri Lanka, repatriation of savings by migrant workers due to uncertain conditions in the major destinations, increase in average wage rate, increased migration to high wage paying countries like Korea and Singapore were regarded as the major factors that assisted this improved performance in workers' remittances.

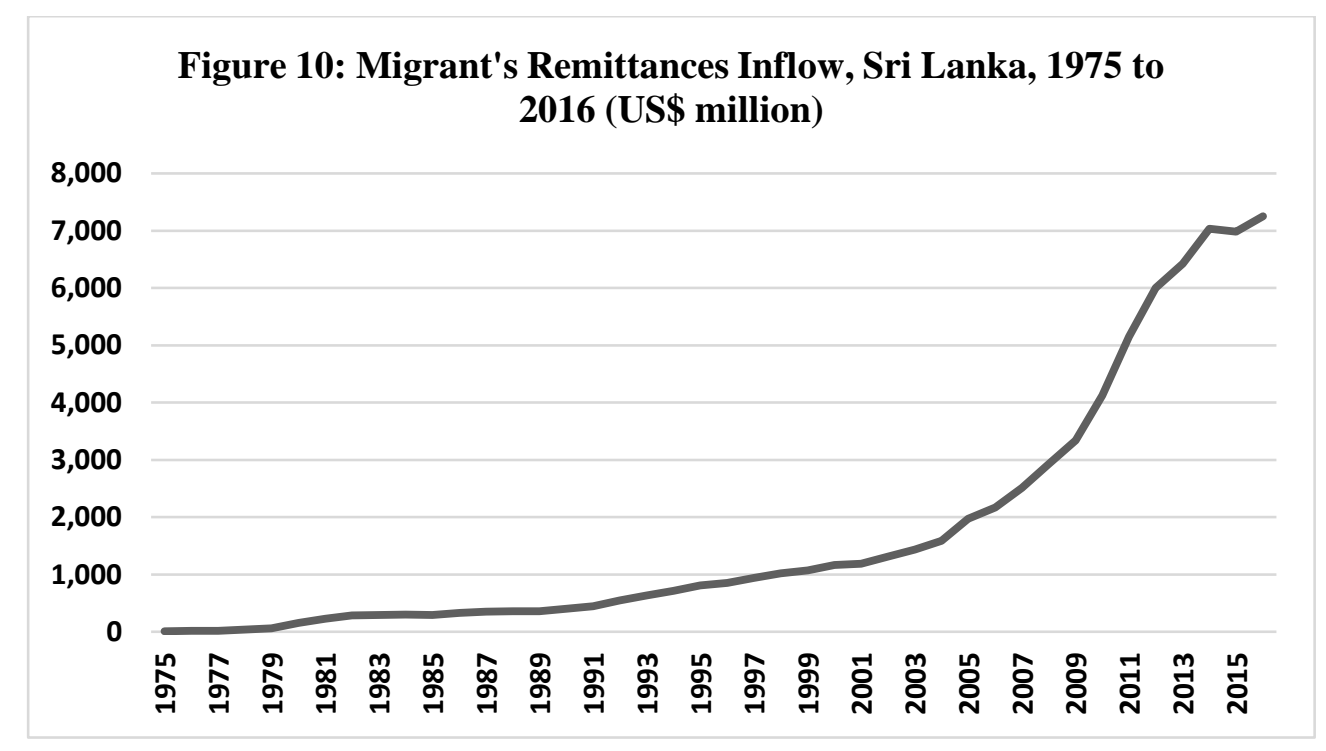

Source: Drawn from http://www.worldbank.org/en/news/press-release/2017/04/21/remittances-todeveloping-countries-decline-for-second-consecutive-year

Main drivers for current international migration trend appear to be employment and education. According to 2012 census data, 85 percent have migrated for employment

\footnotetext{
${ }^{13} \mathrm{http}: / /$ www.cbsl.gov.lk/pics_n_docs/10_pub/_docs/efr/annual_report/AR2016/English/5_Chapter_01.pdf ${ }^{14} \mathrm{http}: / /$ www.treasury.gov.lk/documents/10181/12870/2014/23cd697c-85b6-4ad6-8ba32a007be8b56e? version $=1.0$
} 


\section{Migration in Sri Lanka: To be recognized as a key enabler for development}

while 7 percent have migrated for educational purpose. The total number emigrated from Sri Lanka on employment abroad amounts to 1.8 million people while 250,000 annually migrate from the island. This consists of 23 percent of the total employment in the country and 21 percent of the labour force.

By recognizing the importance of foreign employment of this nature to the growth of the economy with the reduction of unemployment, the Sri Lankan government has commenced a number of programmes to increase the migration of skilled workers while reducing the unskilled labour migration as country still experiences large outflow of unskilled workers in search of overseas jobs though it has declined to 66 percent. It is also anticipated that to change the composition of the workers' remittances with the government policy to discourage migration of unskilled labour while encouraging semiskilled and skilled labour including professionals to high income economies ${ }^{15}$. In the recent years, labor migration of skilled workers including professionals increased by 12.5 percent whereas the migration of semi-skilled and unskilled workers has decreased by 23.2 percent. It is quite striking to note that the gender balance in the foreign migrants has shifted from the female dominated structure prior to 2007 to male dominated in 2015 by representing 65.6 percent men and 34.4 percent women ${ }^{16}$.

After Sri Lanka began to encourage labour migration to the Middle-Eastern countries, international migration gradually built into a 'migration industry'. Although a coherent framework for governing labour migration is in place for Sri Lanka, a substantial proportion of migrants prefer to take up the informal channel to organize their migration. This suggests that the lack of licensed recruitment agencies in some of their district of residence can make those who intend to migrate vulnerable in the hands of unauthorized agents. Sri Lankan international migration has gradually shifted from an individual or family affair to a process which involved a third party to become a business or industry.

Recommendation 1: Mainstream migration in a comprehensive and focused manner in policy documents and national development plans. Sri Lanka should view migration as relevant for sustainable, inclusive and equitable growth and development, and should

\footnotetext{
${ }^{15} \mathrm{http}: / /$ www.treasury.gov.lk/documents/10181/12870/2015/68f51df3-5465-4805-ab6f$4 \mathrm{a} 024 \mathrm{ec} 672 \mathrm{f} 6$ ? version=1.1

${ }^{16} \mathrm{http} / / /$ www.slbfe.lk/file.php?FID=254
} 
FGS - CJMR Colombo Journal of Multi - Disciplinary Research

include migration in development and sectoral planning. Migration offers a driving force for sustainable development through the effects of globalization. It reduces unemployment and improves human capital.

Recommendation 2: Generate reliable data on migration in order to formulate more effective policy. Although mobility of Sri Lankan people has grown rapidly, data collection and data quality have not kept pace. Yet reliable, high-quality data is essential for countering misinformation as well as for formulating more effective policy. Measuring migration is challenging because of widespread undocumented movement of people, however. Census and surveys on migration need to adequately capture data on short-term migration and multiple reasons for migration. Encourage researchers to develop district migration profiles, including district-wise mapping of nature, timing, duration and magnitude of migration cycles. Furthermore, increase research on sectorwise contribution of migrants in different industries of the economy, including their contribution to GDP and domestic remittances which are currently lacking and imperative for policy formulation.

Recommendation 3: Lessen the harmful effects of internal migration by implementing pro-poor development strategies in backward areas by providing sustainable livelihood opportunities, increased access to social and physical infrastructure and governance institutions in sending areas and crafting prospects for access to credit.

Recommendation 4: It is quite important to Sensitize and train policymakers, regarding obstacles in accessing public services for internal migrants. State and non-state sector organizations must consider age- and gender-specific risks and vulnerabilities of children and that increase essential services for mothers, newborns and children at critical life stages. It is imperative to constitute child protection and vigilance committees at local level to track child migration and prevent trafficking.

Recommendation 5: Home countries and host countries should take a shared approach to human capital development in the context of temporary international labour migration. It is quite apparent that the age-sex structure changes and labour market transformation driven by international migration in both developing and developed countries will lead to increased demand for migrant labour in the future. In this context, it is essential to 


\section{Migration in Sri Lanka: To be recognized as a key enabler for development}

develop programmes that improve the skills of the migrants to suit qualifications demanded by employment opportunities in the labour receiving countries. Constant dialogue has to be carried out between labour-sending and labour-receiving countries to guarantee the quality of the labour, which should integrate skills training within the framework of human capital development. Similarly, such programmes should include mechanisms to meet the personal needs and aspirations of the migrants themselves. This will in turn facilitate to minimize irregular migration flows; secure financial transactions; and improve the health and social welfare of migrants as well as their families.

\section{References:}

Beijer, G.(1970). International and National Migratory Movements. International Migration, VIII(3), 93-109.

Black, R., Natali, C. and Skinner, J. (2005). Migration and Inequality, Equity \& Development, World Development Report 2006, Background Papers, Development Research Centre on Migration, University of Sussex.

Hugo, G. \& Dissanayake. (2014). The Process of Sri Lankan Migration to Australia Focussing on Irregular Migrants Seeking Asylum, Irregular Migration Research Programme Occasional Paper Series 10|2014, Australia: Irregular Migration Research and Analysis Section Department of Immigration and Border Protection.

Hugo, G. (2013). Sri Lankan Migration to Australia, Sri Lanka Journal of Population Studies, 14, $1-32$.

International Organization of Migration, (2005) Migration, Development, Poverty Reduction in Asia, Geneva: International Organization of Migration.

Jayasuriya, D. \& McAuliffe, M. (2013). Placing Recent Sri Lankan Maritime Arrivals in a Broader Migration Context, Australia: Department of Immigration and Border Protection.

Kapur, D. (2003) Remittances: The New Development Mantra, Geneva: United Nations.

Massey, Douglas S. (1988). Economic Development and International Migration in Comparative Perspective, Population and Development Review, Vo. 14(3): 383-413.

Overseas Development Institute. (2006). Internal migration, poverty and development in Asia, ODI Briefing Paper 11, London: Overseas Development Institute. 
FGS - CJMR Colombo Journal of Multi - Disciplinary Research

Edward, T.J. (2006). International Migration and Economic Development, International Symposium on international Migration and Development, Department of Economic and Social Affairs, United Secretariat, Italy.

World Bank. (2006). Global Economic Prospects 2006: Economic Implications of Remittances and Migration, Washington D.C.: World Bank.

World Bank. (2013). World Development Indicators, Washington DC: World Bank. 